\title{
SEJAMOS CúMPLICES da CONSTRUÇÃo DE POSSÍVEIS FUTUROS: TRAVESTI - UNA TEORÍA LO SUFICIENTEMENTE BUENA ${ }^{* 1}$
}

\author{
Let's be allies in paving possible futures: Travesti \\ - una teoría lo suficientemente buena
}

\author{
Rosângela Fachel de Medeiros ${ }^{1}$ \\ ${ }^{1}$ Universidade Federal de Pelotas. Pelotas, RS, Brasil. \\ E-mail: rosangelafachel@gmail.com
}

EDITOR-CHEFE:

Gerson Roberto Neumann

EDITOR EXECUTIVO:

Regina Zilberman

SUBMETIDO: 30.04 .2021

ACEITO: 15.06 .2021

\section{COMO CITAR:}

MEDEIROS, Rosângela

Fachel de. Sejamos cúmplices

da construção de possíveis

futuros: Travesti - una

teoría lo suficientemente

buena. Revista Brasileira

de Literatura Comparada, v. 23 , n. 44 , p. 253-258, set.dez., 2021. doi: https:// doi.org/10.1590/2596-

$304 \times 20212344 \mathrm{rfm}$
Muitos são os triunfos que obtivemos nestes anos. Agora é a hora de resistir, de lutar pela continuidade. A hora da revolução

é agora, porque nunca mais voltaremos para a prisão. Estou convencida de que o motor da mudança é o amor. $O$ amor que nos foi negado é nosso impulso para mudar o mundo. Todos os golpes e o desprezo que sofri, não se comparam com o amor infinito que me cerca neste momento. Fúria Travesti Sempre!

Lohana Berkins ${ }^{2}$ Salta, 1965; Buenos Aires, 2016 tradução da autora

Falamos por experiência Convocamos ao abraço, a passar vergonha em praça pública abraçando nossos corpos injuriosos, a enxugar nossas lágrimas, Te chamamos ao silêncio, cansadas de gritar que nos estão matando. Marlene Wayar, 2017, tradução da autora

1 Resenha de: WAYAR, Marlene, Travesti. Una teoría lo suficientemente buena, Buenos Aires: Muchas Nueces, 2018.

2 Fundadora da Asociación de Lucha por la Identidad Travesti y Transexual (ALITT), em 1994, que presidiu até sua morte. Liderou a criação da Cooperativa Têxtil Nadia Echazú, em 2008, primeira escola cooperativa de travestis e trans, batizada em homenagem à militante pelos direitos das travestis e trans Nadia Echazu. Em 2010, conformou a Frente Nacional por la Ley de Identidad de Género. Publicou os artigos "Un itinerario político del travestismo" (2003), "Eternamente atrapadas por el sexo" (2004), "Travestis: una identidad política"(2008), "Travestismo, transsexualidad y transgeneridad"(2010). Publicou os livros: Cumbia, copeteo y lágrimas. (2007) e Escrituras, polimorfías e identidades (2008). Atuou na organização das publicações: La gesta del nombre propio: informe sobre la situación de la comunidad travesti en la Argentina (2005) e Diálogo: prostituición/trabajo sexual: las protagonistas hablan (2007). 
$\mathrm{E}$ m Travesti - una teoría lo suficientemente buena, Marlene Wayar ${ }^{1}$ (natural de Córdoba, Argentina, 1968) - escritora, artista, pensadora e ativista travesti pelos Direitos Humanos e pelas Infâncias Livres - apresenta-nos uma teoria orgânica, que, em suas palavras, precisa passar pelo corpo para ser colocada em prática. Publicado pelo editorial cooperativo Muchas Nueces, o livro é uma obra híbrida que imbrica fotografias da autora (realizadas por Lina Etchesuri) e ilustrações (de Nina Kunan) a diferentes gêneros textuais e vozes, combinando a perspectiva ensaística ao testemunho íntimo das experiências em um convite ao diálogo, discurso que constitui a publicação, por meio do entrelaçamento de textos marcados pela força apaixonante da oralidade.

A abertura do livro está a cargo do afetuoso "Prólogo", escrito por Susy Shock ${ }^{2}$ (natural de Buenos Aires, Argentina, 1968 - que se apresenta como artista, trans, sudaka ${ }^{3}$ ), que nos convida a conhecermos Marlene Wayar, não apenas por seu currículo ativista ou por seus títulos acadêmicos, mas buscando desvelar um pouco da essência visceral que a mobiliza a seguir tecendo uma teoria travesti-trans em um mundo de absolutos fracassos. "Todos os fracassos!” Ausências, desprezos, faltas de abraços e de direitos, expulsão do lar heterossexual, acolhimento das ruas, da pobreza, da prostituição, e o vaticínio, ainda vigente, de uma morte jovem. De que paciência, de que madeira e de que sonhos está feita Wayar para seguir ruminando e dedicando tanto de seu tempo a essas inquietações - muito além da média acadêmica, feminista, ativista e da classe média de todas as escolas - se pergunta, e nos pergunta, Susy Shock. Para então concluir, quase como um manifesto, que Wayar está feita de uma poética que é a própria criança abraçada, a garotinha amada, que segue compartilhando poesia, porque não foi destruída completamente e foi sendo incubada em meio a todas as fúrias, as dores, os ressentimentos e as enormes batalhas.

O encerramento do prólogo de Susy Shock anuncia uma das perspectivas centrais da teoria travesti-trans em processo proposta por Wayar, que será apresentada no primeiro capítulo do livro - "Palabras de fuego. Teoría travesti-trans sudamericana" - a necessidade de pensarmos as questões de gênero a partir das infâncias. Porque, para Wayar, a infância é o tempo e o espaço "adequados e oportunos para a indagação, a transformação e a identificação" (WAYAR, 2018, p. 18, tradução da autora), pois há nas infâncias uma potência inusitada, que já não se restringe à construção de uma subjetividade em contraposição a uma outridade, mas desvela um espaço potente para a construção de

\footnotetext{
1 É Comunicadora Social formada em Psicologia Social pela Universidad Popular de las Madres de Plaza de Mayo e, também, em Pedagogia. É coordenadora geral da organização Futuro Transgenerico, que formou parte da Frente Nacional pela Lei de Identidade de Gênero, na Argentina, e cofundadora da Red Trans de Latinoamérica e Caribe "Silvia Rivera". É diretora do El Teje, primeira revista travesti da América Latina. É uma das fundadoras da Cooperativa Têxtil Nadia Echazú. Foi apresentadora do ciclo "Género identidad. La diversidad en el cine” (2011), emitido pelo Canal Encuentro. Integra o Consejo Asesor Ad Honorem do Ministério das Mulheres, Gênero e Diversidade, da Argentina, criado em 2020. Atuou como colunista do suplemento Soy, de Pagina 12, e da Revista Anfibia, da Universidad Nacional de San Martín. Recebeu os prêmios: "El laurel de los DD.HH", do Movimiento Antidiscriminatorio Liberación, Diana Sacayán; "Lola Mora”, da Legislatura de la Ciudad de Buenos Aires; e "El rodete de Evita", do suplemento Soy.

2 Autora de Revuelo sur (coleção de poesías) 2007; Poemario Trans Pirado, com ilustrações de Enrique Gurpegui e prólogo de Marlene Wayar (2011); Relatos en Canecalón, com prólogo de Fernando Noy (2011); Crianzas, com ilustrações de Anahí Bazán Jara e prólogos de Marlene Wayar e Claudia Acuña, (2016); Hojarascas, com fotografias do "M.A.f.I.A." (2017); Realidades. poesía reunida con ilustraciones, de Fernando Noy y León Ferrari (2020). E protagonizou uma das edições da Série Anti-Princesas, do editorial Chirimbote - Susy Shock para chicxs, de Nadia Fink e Pitu Saá. Como compositora e cantora, lançou os discos Buena vida y poca vergüenza (2014) e Traviarcado, (2019). E participou nos filmes: Mia (2010), Andrea. Un melodrama rioplatense (2013), e em Escenas de una fiesta rota e Deconstrucción, crónicas de Susy Shock, ambos de 2016.

3 Uma forma depreciativa de se referir as pessoas de origem sul-americana, derivada da palavra sudamericano (em espanhol).
} 
uma NOSTREDAD 4 , uma subjetividade "nossa" - em comum, compartilhada - capaz de despertar a consciência social e a empatia mútua. E que pode ser acionada pela potência dos encontros (ainda não severamente cerceados pelos adultos), que promovem a identificação apesar das diferenças. Assim, para Wayar, a infância é o tempo e a cartografia em que podemos construir essa terceira opção à dicotomia identidade(eu)/outridade, a NOSTREDAD. E, conforme a autora, é a essa instância infantil que ela vai recorrer em suas oficinas para convocar seus participantes a encontrarem seu SER Trans e, assim, implicarem-se em uma transformação a partir de seus registros da infância.

Observamo-nos em nossas infâncias e percebemos as violências que cada um sofreu por conta do regime heterossexista e adultocêntrico, o desejado e o reprimido, emprestamos voz e ouvidos a nossa própria criança e a tudo aquilo que viveu como carências, como pactos rompidos entre o mundo adulto e essa infância. E, em seguida, nos perguntamos: o que há em comum entre como me sonhei e um homem ou uma mulher? (WAYAR, 2018, p. 24, tradução da autora)

E, segue Wayar, explicando que após essa reflexão não interessa à experiência travesti definir O QUE sou, como uma identidade fechada em algum momento, mas, sim, definir o que NÃO SOU: "não sou fundamentalista, genocida, assaltante, assassino/a, torturador/a, cruel, terrorista, etc.. E com essa NOSTREDAD, a partir da des-identificação, que nos conhecemos. "O NÃO nos define tanto ou mais que o SIM”. E se, até hoje, a humanidade é entendida a partir de um CIStema ${ }^{5}$ heterocentrado binário homem-mulher, é desde a teoria travesti-trans sul-americana que Wayar vai afirmar, citando Susy Shock: "Não queremos mais ser esta humanidade" e, dizendo isso, tenta também sair do par sistêmico, completando: "Não sou homem, não sou mulher, hoje vou sendo travesti" (WAYAR, 2018, p. 25, tradução da autora). E, evocando os saberes bichas, sapatões e travas infantes, que colocam em xeque a responsabilidade social das funções materno-paternais que alicerçam o sistema heterossexual, Wayar denuncia o fracasso do Estado em garantir os direitos de crianças e adolescentes. E conclui, afirmando que esse Estado, que não entende suas funções materno-paternais e as implicações daí decorrentes, representa o fracasso político dessa sociedade e de seus governos, e originou um território devastado. Uma devastação que "é, também, e antes de mais nada, da infância” (WAYAR, 2018, p. 26, tradução da autora).

Após essa introdução de fogo à teoria travesti-trans sul-americana, Wayar a segue tecendo por meio de uma poética dialógica e afetiva, que entrelaça experiências e reflexões, compondo um discurso coletivo e plural.

No capítulo "El arte de re-sentir - Puentes transfronterizos entre lo oral y lo escrito", Wayar convoca a escritora Claudia Rodríguez ${ }^{6}$ (natural de Santiago de Chile, Chile, 1968 - que se apresenta como ativista, travesti, pobre e ressentida) para uma conversa, na qual, através da interlocução de suas experiências, buscam construir conhecimentos desde suas pobrezas e dar corpo à teoria travesti-trans

4 Neologismo criado pela combinação das palavras nuestra (nossa) e identidad (identidade) para designar uma "identidade nossa".

5 Escolhemos utilizar o neologismo CIStema, utilizando a letra $\mathrm{C}$ ao invés de $\mathrm{S}$, para dar a ver a hegemonia da perspectiva cisgênero em todos os âmbitos normativos e performativos da sociedade.

6 Claudia Rodriguez é ativista no Movimento Histórico de Libertação Homossexual (Movilh), desde 1991, diplomada em Gênero pela Faculdade de Filosofia e Humanidades do Chile, com vasta experiência em formação em Direitos Humanos e ITS. É autora de três antologias de poesias e textos: Dramas Pobres, Enferma del Alma e Manifiesto Horrorista, primeiramente autopublicados no formato de fanzines e, em 2021, publicados conjuntamente sob o título Poesía Travesti, Resentía y Furiosa pela editora Té de Boldo; e da obra teatral Cuerpos para odiar: Sobre nuestras muertes, las travestis, no sabemos escribir (2013-2014). 
sul-americana, como uma poética alicerçada na arte - de construir, de acreditar em si mesmo e de empoderar-se - que tem como objetivo melhorar o mundo para as gerações que virão. Em um diálogo franco e sem pudores, elas expõem suas raivas e suas dores, e também as companheiras mortas que carregam em suas memórias, como um "cemitério na cabeça”. E, nesse sentido, Claudia Rodríguez conta a Wayar que não saber falar, principalmente, não conseguir dizer "Isso está me machucando" é a causa de seu imenso ressentimento. E, buscando compartilhar suas percepções, lê para Wayar um trecho de sua obra de teatro Cuerpos para odiar (2013-2014), no qual ela fala das dores de sua infância.

Deveria ter adivinhado que a infância não era nem fluxo nem enunciação, mas apenas uma maneira devidamente forçada e deficiente de chegar ao mundo. As palavras me desviaram, se transformaram em forças avassaladoras que apagaram toda a minha memória. Quem sabe, para mim, a infância nem existiu. Em mim, cada instante estava presente sem um antes ou depois até que na escola me gritaram: “Mulherzinha!” "Viado!” "Bichona!”. (RODRÍGUEZ apud WAYAR, 2018, p. 32, tradução da autora)

E, talvez por tudo isso, Claudia afirma a Wayar que faz questão de falar de seus fracassos - com o silicone e com a prevenção à aids - e da forma como percebe que a intimidade das vidas está imbricada aos problemas sociais. De como, no Chile, os problemas e as necessidades da comunidade travesti - saúde, habitação, educação - são demandas da luta de classes que, no entanto, são excluídas dos debates da classe trabalhadora do país. E segue seu raciocínio, afirmando que os pobres seguirem se matando e que o pobre mate a uma travesti parece ser oportuno para o sistema. Em resposta à dureza dessa realidade, Wayar diz que, em alguma medida, é preciso romper com os estereótipos de ódio, de discriminação e de morte, e para isso estão as travestis, "para colocar novas cartas sobre a mesa”, completa Claudia Rodríguez.

O capítulo seguinte, "Rituales dialogados. Herramientas para una era post-alfabética. Clase con Susy Shock en MU”, apresenta uma conversa de Wayar e Susy Shock com estudantes da Cooperativa lavaca, mediada por Sergio Ciancaglini, em uma aula sobre comunicação social. Nessa conversa, Susy Shock coloca em questão o papel dos meios de comunicação na configuração e manutenção de um mundo compulsoriamente heterossexual, afirmando que eles seguem, dia a dia, construindo heterossexualidade. Mas, segue Shock, o que colocamos em xeque não é a heterossexualidade ou não de cada pessoa, mas a forma como esse CIStema heterossexual - hegemônico e violento - que leva milênios construindo uma sociedade desigual e horrorosa, é um fracasso. E, novamente, é referida a infância - "Porque na intriga, na busca, no comover-se com o corpo, está precisamente a questão nodal da infância" (WAYAR, 2018, p. 79, tradução da autora) - como momento crucial da vida de cada pessoa. Nesse sentido, Wayar destaca os pactos heterossexuais que atravessam a sociedade e as famílias, e conclama os heterossexuais a fugirem desse CIStema em um movimento de des-identificação em relação às posições, saberes e práticas que sustentam as opressões. Perspectiva que é corroborada por Susy Shock que, fazendo referência a seu livro Crianzas (2016), alerta para o fato de que a questão não é discutir a respeito das crianças trans, mas, sim, questionar essa sociedade heterossexual que segue destruindo infâncias e negando a algumas crianças o direito ao afeto e aos abraços. E como resposta a esse contexto de opressões, Wayar coloca em pauta o trabalho sexual e a importância das outridades que se aproximam com empatia. 
"Sin eufemismos. Palabras vivas y vividas para una descolonización. Entrevista de Claudia Acuña" é o último capítulo do livro e apresenta uma entrevista concedida por Wayar à jornalista e escritora Claudia Acuña, que tem como eixo central a discussão dos Direitos Humanos em uma perspectiva interseccional. Para Wayar, falar em direitos humanos diz respeito à dignidade que é intrínseca ao fato de ser humanos, e é a dignidade do direito à vida, a transitar, à beleza, à diversão, à felicidade, ao abraço e ao amor (WAYAR, 2018, p. 100, tradução da autora) que nos une. Dignidade que, assim como a teoria travesti-trans, deve passar pelo corpo. Porque, como afirma Wayar, é sobre o corpo que incide a longa agonia mortal dos maus-tratos, que buscam conquistá-lo, da mesma forma como a conquista de um território, levada adiante por violações massivas. E, completa, "sempre somos esse território tão cruelmente maltratado" (WAYAR, 2018, p. 96, tradução da autora). Para, então, a partir desse sofrimento e ressentimento reivindicar o amor - um amor responsável - renegando a posição de vítima e assumindo o lugar de sobrevivente, como uma posição política para reclamar por leis, mas sobretudo, por uma política de reparação.

O livro encerra com o anexo - "Gritazos. Romper el paradigma hetero-winka-patriarcal” - que apresenta dois discursos de intensa força transformadora de Wayar. A transcrição do manifesto "Nuestros Porqués”, lido por Wayar na Vigília Trans, realizada na Praça de Maio em 17 de agosto de 2017, como um abraço à memória de Ayelén Gómez, jovem travesti assassinada pela polícia de Tucumã - cuja convocatória final é apresentada como um dos prefácios dessa resenha. E a matéria "Habeas Corpus", publicada na revista $M U$, em julho de 2009, na qual Wayar responde de maneira sincera e pedagógica a questões referentes às (des)identidades travesti, a seus afetos e a suas corporalidades desobedientes, assim como em relação à maternidade e às reivindicações políticas e sociais. E fala, também, sobre como as rupturas travesti e trans com o CIStema heterossexual podem levar à marginalização e à pobreza que, muitas vezes, só encontra como resposta a prostituição. E é da experiência dessas vivências que Wayar vai encerrar o texto convocando a "des-identificarmo-nos de todo o preestabelecido para voltar a construir uma identidade, tendo a memória do passado, mas também com esperança no futuro" (WAYAR, 2018, p. 124, tradução da autora). E se não sabemos que identidades seremos capazes de criar juntos, por agora, sugere Wayar, podemos partir de uma, a "pessoa humana".

Comprometida com seu tempo e com seu contexto político e social sul-americano, Wayar denuncia os diversos crimes cometidos pelo CIStema heteropatriarcal capitalista desse território de guerra que é a heterossexualidade. E para enfrentá-los nos convoca a buscarmos a travesti que há em nós, porque, como nos explica a autora, para entendermos o que é ser travesti, é preciso implicar-se, é preciso entender o que é "trava” em nós e ver como isso nos atravessa. E por meio desse exercício teórico-poético travesti-trans, Wayar nos convida a sermos cúmplices da construção de possíveis futuros, e a nos comprometermos com a produção de uma sociedade que se abraça e que ama a si mesma. Complicado? - nos pergunta Wayar, pois então, "esforcemo-nos um pouco mais. É simples" (WAYAR, 2018, p. 26, tradução da autora). 


\section{REFERÊNCIAS}

RODRÍGUEZ, Claudia. Cuerpos para odiar: sobre nuestras muertes, las travestis, no sabemos escribir (2013 - 2014). Patagonia: Ají Ediciones, 2018.

SHOCK, Susy. Crianzas. Buenos Aires: Muchas Nueces, 2016.

WAYAR, Marlene. Travesti. Una teoría lo suficientemente Buena. Buenos Aires: Muchas Nueces, 2018. 